\title{
Efficacy of enrofloxacin in the treatment of naturally occurring acute clinical Escherichia coli mastitis
}

\author{
L. Suojala, ${ }^{* 1}$ H. Simojoki, ${ }^{*}$ K. Mustonen, $\dagger$ L. Kaartinen, $\ddagger$ and S. Pyörälä* \\ *Department of Production Animal Medicine, Faculty of Veterinary Medicine, University of Helsinki, Paroninkuja 20, FI-04920 Saarentaus, Finland \\ †Vetcare Ltd., P.B. 26, FI-04601 Mäntsälä, Finland \\ $\ddagger$ Veterinary Virology Research Unit, Finnish Food Safety Authority Evira, Mustialankatu 3, FI-00790 Helsinki, Finland
}

\section{ABSTRACT}

The efficacy of the combination of systemic enrofloxacin $(5 \mathrm{mg} / \mathrm{kg}$ twice with a 24 -h interval, first dose i.v., second dose s.c.) and the nonsteroidal antiinflammatory agent ketoprofen $(3 \mathrm{mg} / \mathrm{kg}$ i.m. or $4 \mathrm{mg} / \mathrm{kg}$ per os daily for 1 to $3 \mathrm{~d}$ ) treatment was compared with antiinflammatory treatment only in dairy cows with naturally occurring acute clinical Escherichia coli mastitis. A total of 132 cows with acute clinical mastitis and with confirmed growth of $E$. coli in a pretreatment milk sample were randomly allocated to 1 of 2 treatment groups. Response to treatment was evaluated clinically and by bacteriological culturing and determination of N-acetyl$\beta$-D-glucosaminidase (NAGase) activity on d 2 and 21 posttreatment. Enrofloxacin treatment did not increase bacteriological (90.5\% of treated vs. $86.8 \%$ of nontreated cured) or clinical cure (46.7\% of treated vs. $57.1 \%$ of nontreated cured), cow survival (95.3\% of treated vs. $92.7 \%$ of nontreated), or quarter milk production assessed $21 \mathrm{~d}$ posttreatment ( 21.8 vs. $29.3 \%$ return to preinfection level for nontreated cows), nor did it decrease mammary gland tissue damage estimated using determination of milk NAGase activity $(24.0 \pm 0.3$ vs. $18.3 \pm 1.3 \mathrm{pmol}$ of 4 -methylumbelliferone per min per $\mu \mathrm{L}$ for nontreated cows). Treatment did not influence the number of study cows remaining in the herd after 6 mo ( $71.9 \%$ of treated vs. $80.6 \%$ of nontreated). The only significant effects of enrofloxacin were enhancing the bacteriological cure (odds ratio $=3.32$ for treated cows) and decreasing the clinical cure (odds ratio = 0.05 for treated cows) on d 2 posttreatment. Our results did not support the use of enrofloxacin to treat acute clinical E. coli mastitis.

Key words: antimicrobial treatment, bovine mastitis, enrofloxacin, Escherichia coli

Received June 6, 2009.

Accepted January 8, 2010.

${ }^{1}$ Corresponding author: leena.suojala@fimnet.fi

\section{INTRODUCTION}

Clinical mastitis caused by Escherichia coli is generally considered self-limiting and of short duration (Burvenich et al., 2003). Nevertheless, especially during early lactation, E. coli mastitis is associated with severe clinical signs, loss of milk production, and grave tissue damage to the mammary gland because of the release of endotoxin and the associated host response (Golodetz and White, 1983).

The treatment of E. coli mastitis has focused on the use of antiinflammatory agents, which alleviate clinical signs and improve the general condition of the cow. Several nonsteroidal antiinflammatory agents have shown efficacy in reducing inflammatory reactions in experimental mastitis (Lohuis et al., 1989; Banting et al., 2008), but field trials are scant (Shpigel et al., 1994; McDougall et al., 2009). Results from the field studies are difficult to evaluate because combinations of different treatments were used and the treatment was not specifically for $E$. coli mastitis, but for coliform mastitis or clinical mastitis.

Systemic administration of antimicrobials was recommended for the treatment of severe coliform mastitis because of the risk of bacteremia (Cebra et al., 1996; Wenz et al., 2001). Few antimicrobial substances were recommended for systemic treatment of coliform mastitis (Constable et al., 2008). Enrofloxacin is a bactericidal, concentration-dependent fluoroquinolone antimicrobial approved for dairy cattle in the European Union. High concentrations of its active metabolite, ciprofloxacin, are reached and maintained in blood and milk (Kaartinen et al., 1995; Rantala et al., 2002). Milk does not significantly interfere with the antimicrobial activity of enrofloxacin in vitro (Fang and Pyörälä, 1996). Fluoroquinolones can have positive immunomodulatory effects by increasing the killing ability of neutrophils (Hoeben et al., 1997).

Results of antimicrobial treatment of E. coli mastitis have been equivocal. No positive effects of antimicrobial treatment were found in experimental E. coli mastitis by Pyörälä et al. (1994), whereas other studies reported faster elimination of bacteria, increased survival of the 
cows, reduced inflammatory reaction, or decreased milk losses (Rantala et al., 2002; Poutrel et al., 2008). Some field studies have shown equal cure rates for E. coli mastitis using antimicrobials to which E. coli are susceptible or nonsusceptible in vitro (Jones and Ward, 1990; Pyörälä and Pyörälä, 1998). The efficacy of enrofloxacin treatment of naturally occurring E. coli mastitis has not been investigated.

The aim of this field study was to compare the efficacy of a combination of systemic enrofloxacin and supportive treatment versus supportive treatment only in dairy cows with acute clinical $E$. coli mastitis.

\section{MATERIALS AND METHODS}

\section{Cows}

Potential candidates included all lactating dairy cows with acute clinical mastitis (IDF, 1999) treated by veterinarians (and which the veterinarian suspected was caused by coliforms) in the practice areas of the Ambulatory Clinic of Helsinki University (Mäntsälä, Finland) and the Lammi Veterinary Practice (Lammi, Finland) during 2003 to 2006. Herds were typical Finnish dairy herds, most being housed in a stanchion barn of 20 to 50 milking cows of Finnish Ayrshire or Holstein Friesian breeds, that received silage-based feeding, were not vaccinated against coliform mastitis, and were milked twice daily. Final inclusion of a cow in the trial was made based on the result of bacteriological examination of the pretreatment milk sample. Only cows with pretreatment milk samples yielding $E$. coli were included. All cows included had only 1 quarter affected. Upon the first visit by the veterinarian, the farmer signed an informed consent form. Days in milk and number of parities $(1,2$, and $\geq 3)$ were recorded. The veterinarian revisited the cow when necessary based on its clinical condition. The study protocol as a clinical treatment trial was approved by the National Agency of Medicines (Helsinki, Finland).

\section{Study Design}

The cows were randomly allocated to 1 of 2 treatment groups, enrofloxacin and nontreated, using cow identification number (even and odd numbers). In the enrofloxacin group, cows were treated systemically with enrofloxacin (Baytril, Bayer HealthCare AG, Leverkusen, Germany). The dosage was $5 \mathrm{mg} / \mathrm{kg}$ of BW administered twice at an interval of $24 \mathrm{~h}$; the first dose was given i.v. by the veterinarian and the second dose s.c. by the owner. Cows in both groups received the nonsteroidal antiinflammatory drug ketoprofen i.v. or i.m. at a dose of $3 \mathrm{mg} / \mathrm{kg}$ of $\mathrm{BW}$ (Comforion, Orion
Oyj, Finland) or $4 \mathrm{mg} / \mathrm{kg}$ per os (Dolovet, Vetcare Oy, Mäntsälä, Finland) daily for 1 to 3 d. Efficacy of the oral treatment was reported to be identical to that achieved with i.m. administration (Banting et al., 2008). Because the clinical diagnosis of E. coli mastitis was not confirmed at the initial farm visit, experimental treatment was combined with intramammary penicillin G (Carepen $600 \mathrm{mg}$, Vetcare Oy) once daily into the affected quarter until confirmation of the diagnosis. Escherichia coli are inherently resistant against penicillin $\mathrm{G}$, so this additional treatment would not be expected to affect the results. Use of frequent milking was the decision of the owner. Fluid therapy was used by the veterinarian when necessary based on clinical signs. All treatments were recorded by the veterinarian on the study data collection form.

\section{Sampling and Laboratory Analyses}

A 4-mL milk sample was collected aseptically from the affected quarter before treatment $(\mathrm{d} 0)$ and $2 \mathrm{~d}(\mathrm{~d}$ 2 ) and 3 to $4 \mathrm{wk}$ (d 21) posttreatment by the veterinarian or a trained owner. A sample of $0.01 \mathrm{~mL}$ of milk was cultured on blood agar (6 to $10 \%$ sheep blood; Tammertutka, Tampere, Finland). Isolates were identified as E. coli by colony morphology, Gram stain, and typical growth on eosin methylene blue agar (Hogan et al., 1999). The amount of growth in the pretreatment sample allowed classification into 2 groups, $<10 \mathrm{cfu}$ and $\geq 10 \mathrm{cfu}$ in $10 \mu \mathrm{L}$ of milk, with a detection limit of 100 $\mathrm{cfu} / \mathrm{mL}$. Growth of a minimum of 3 similar colonies was regarded as a positive diagnosis. The diagnosis was confirmed by the API 20E test (bioMérieux, Marcy l'Etoile, France) at the Finnish Food Safety Authority Evira (Helsinki, Finland). Follow-up milk samples taken on d 2 and 21 were stored frozen and cultured within a month. If bacteria other than $E$. coli were isolated in follow-up sample on d 21, the quarter was defined as reinfected. Antimicrobial susceptibility of the E. coli isolates in vitro was tested by the VetMIC microdilution method (SVA, Uppsala, Sweden; CLSI, 2004) at the Finnish Food Safety Authority Evira (Helsinki, Finland) using a threshold of $>0.06 \mu \mathrm{g} / \mathrm{mL}$ for susceptibility to ciprofloxacin. All isolates were susceptible to ciprofloxacin. If growth of $E$. coli was detected in both pre- and posttreatment samples, isolates were genotyped using pulsed-field gel electrophoresis (PFGE) at the Finnish Food Safety Authority Evira (Kuopio, Finland). DNA was extracted, digested with $X b a l$, and subjected to PFGE essentially according to the CDC PulseNet protocol for E. coli O157:H7 (CDC, 2008). Salmonella Braenderup strain H9812 DNA digested with $X b a l$ was used as a DNA size standard. The PFGE patterns were analyzed for similarity by visual compari- 
son. Strains were considered distinct if the pulsotypes were not identical.

Milk N-acetyl- $\beta$-D-glucosaminidase (NAGase) activity, an indicator of the degree of inflammation and tissue damage of the affected quarter, was measured using the fluorogenic NAGase assay method described by Mattila and Sandholm (1986). Inter- and intraassay coefficients of variation (CV) for NAGase activity were $<4.8 \%$ for the high control and $\leq 6.6 \%$ for the low control. Milk NAGase activity values $>24.49$ pmol of 4-methylumbelliferone (4-MU) per $\mathrm{min} / \mu \mathrm{L}$ were recorded as $24.49 \mathrm{pmol}$ of 4 -MU per min/ $\mu \mathrm{L}$ (the upper limit for quantification). Activity of NAGase cannot be measured in milk with extreme variation in consistency and these samples were excluded from the analyses.

\section{Clinical Examination and Data Recording}

At the time of enrollment (d 0), each cow was examined clinically by the attending veterinarian. Clinical signs (local signs such as swelling and pain in the udder, milk appearance, and systemic signs such as rectal temperature, general attitude, and appetite) and California Mastitis Test scores using the scoring system from 1 to 5 were recorded on the data collection form. Clinical signs were scored according to a 3 -point scale $(1=$ no signs to $3=$ severe signs) as described previously (Pyörälä et al., 1994). The cases with clinical scores $\leq 1.5$ were considered mild and those with scores $\geq 2$ moderate to severe. On d 2 and at 3 to 4 wk (defined as d 21) posttreatment, the farmer estimated quarter milk production (normal, diminished, or a blind quarter) and clinical recovery (visible or palpable signs) of the affected quarter, carried out a California Mastitis Test, and recorded the results on the data collection form according to oral and written instructions. Frequent milking (emptying of the infected quarter at least twice daily in addition to the regular 2 milkings/d) at the acute stage was recorded.

\section{Assessment of Treatment Outcome}

Clinical and bacteriological cures on d 2 and d 21 and return to milk production of the affected quarter on d 21 compared with quarter milk production before mastitis (returned, diminished, blind quarter) as estimated by the owner were assessed. A cow was defined as clinically cured if no systemic signs were present, the affected quarter was free from any clinical signs, the milk appearance was normal, and the milk was acceptable for delivery. Growth of E. coli in the follow-up milk samples on d 2 and 21 was used to assess the bacteriological cure.
A cow was classified as "survived" if it remained in the herd (not dead, killed, or culled because of E. coli mastitis) during the 3 -wk posttreatment period. To evaluate the long-term presence of the cow in the herd, the farmer was asked 6 mo later if the cow was still in the herd, after which the cow was classified as remaining or not remaining.

\section{Statistical Analysis}

After validation checks for data inconsistencies and missing entries, statistical analyses were carried out using Stata Intercooler version 9.0 (Stata Corp., College Station, TX). The unit for analysis was the cow. The outcomes were bacteriological cure on d 2 and 21 (yes vs. no), clinical cure on d 2 and 21 (yes vs. no), survival during 3 -wk study period (yes vs. no), NAGase activity on d 21, return of milk production of infected quarter on d 21 (returned vs. not returned), and remaining in the herd 6 mo after treatment (yes vs. no). Logistic and linear regression models were used as described below. Clustering effect of a herd was estimated by using logistic and linear mixed models.

Continuous variables (DIM and milk NAGase activities) were examined for linearity with the outcomes. To improve linearity, NAGase activity on d 0 and 21 was logarithmically (natural logarithmic) transformed; NAGase activity on d 2 was bimodally distributed and therefore, for the purposes of the analysis the activity at this time was analyzed dichotomously (values $<10 \mathrm{pmol}$ of $4-\mathrm{MU}$ per min $/ \mu \mathrm{L}$ vs. values $\geq 10 \mathrm{pmol}$ of 4 -MU per $\min / \mu \mathrm{L})$. Other dichotomous variables were clinical signs (mild vs. severe), enrofloxacin treatment (yes vs. no), amount of bacterial growth on d $0(<10$ vs. $\geq 10 \mathrm{cfu} / \mu \mathrm{L}$ ), fluid therapy given (yes vs. no), use of frequent milking (yes vs. no), and reinfection on d 21 (yes vs. no). Parity was used as a categorical variable (parities 1,2, and $\geq 3$ ).

The variables were subjected first to univariable and then to multivariable analyses. Variables with a $P$-value $<0.25$ in a univariable analysis were entered into the multivariable analysis. Collinearity was tested with a pairwise correlation test. Enrofloxacin treatment was always kept in the final model. Manual stepwise backward procedures were used in model building. Possible confounding factors (DIM, frequent milking, fluid therapy, and parity) were tested separately with all models and were kept in the analysis if they possibly affected the results. No significant correlation or interactions were found between any of the variables studied. Cows with missing data for any variable in the model were excluded from that analysis.

A multivariable logistic regression model was used for the outcomes bacteriological cure on d 2 and 21, 
clinical cure on d 2 and 21, returning of quarter milk production on $\mathrm{d} 21$, and remaining in the herd after 6 mo. Predictive variables used for bacteriological cure on d 2 were clinical signs on d 0, treatment (enrofloxacin vs. no treatment), fluid therapy, parity, and NAGase activity on $\mathrm{d} 0$. For bacteriological cure on $\mathrm{d}$ 21 , predictive variables were clinical signs on d 0 , treatment, DIM, and parity, but none of the variables had $P$-values $<0.25$ in the univariable analyses. For clinical cure on $\mathrm{d} 2$, predictive variables were clinical signs on d 0, treatment, NAGase activity on d 0, growth, fluid therapy, and frequent milking; and for clinical cure on d 21, clinical cure on d 2, clinical signs on d 0 and 2, treatment, fluid therapy, and NAGase activity on d 0. For return to quarter milk production, predictive values were bacteriological cure on d 2, clinical signs on d 0 and 2, clinical cure on d 2, treatment, fluid therapy, frequent milking, NAGase activity on d 0 and 2, DIM, and parity. Samples with growth of bacteria other than $E$. coli at that time point were excluded from this analysis. For remaining in the herd after 6 mo, predictors were bacteriological cure on d 2, clinical signs on d 0 and 2 , clinical cure on d 2, growth, DIM, treatment, fluid therapy, and NAGase activity on d 0.

For outcome of NAGase activity on d 21, a multiple linear regression model was used. Samples with growth of bacteria other than E. coli at that time point were excluded from the NAGase analysis, because any IMI increases milk NAGase activity. Predictive variables used were clinical signs on d 0 and 2 , treatment, fluid therapy, and NAGase activity on d 0 and 2.

Full and nested models were compared with a likelihood ratio test. Because of the small number of dead or killed cows on d 21, a simple logistic regression model was used to test the effect of survival of a cow. Model fit was assessed with assumptions of normality and homogeneity of variances, which were evaluated by checking the residuals. The 2 -way sample size calculation for the statistical analyses in final models allowed detection of differences of $\geq 25 \%$ between treatment groups for all outcomes evaluated; the power of analyses was 0.80 . For all tests, $P<0.05$ was considered significant.

\section{RESULTS}

\section{Mastitis Cases}

A total of 184 cows were suspected of having acute clinical E. coli mastitis based on clinical signs. Of these, 52 cases were excluded because they had mastitis caused by bacteria other than $E$. coli in the pretreatment sample, they deviated from the study protocol, or for some other reason (e.g., owner request or missing information). In total, 132 cows from 61 dairy farms (mean 2.2 cows per herd) with confirmed growth of $E$. coli in the pretreatment milk sample were finally included (Table 1). All cows had only 1 quarter affected. Median time from the detection of the first clinical signs to the visit by the veterinarian and treatment was $6 \mathrm{~h}$. In $8.4 \%$ of the pretreatment samples, fewer than $10 \mathrm{cfu}$ of $E$. coli/ $\mu \mathrm{L}$ of milk were isolated (Table $1)$. The enrofloxacin-treated group comprised 64 cows (48.5\%) and the nontreated group 68 cows (51.5\%). Age (parity) or DIM of the cows did not differ between the treatment groups.

According to clinical signs on d 0, 80.1\% $(\mathrm{n}=105)$ of the cows had moderate to severe signs (severity score $\geq 2)$ and $19.9 \%(\mathrm{n}=26)$ had mild signs ( All cows receiving fluid therapy $(\mathrm{n}=40)$ had moderate to severe disease. Cows in the enrofloxacin group had no more severe signs than cows in the nontreated group on $\mathrm{d} 0$. Total numbers and mean values of all variables are shown in Table 1.

\section{Bacteriological Cure}

On d 2, E. coli $(\mathrm{n}=72)$, other coliforms $(\mathrm{n}=2)$, and other bacteria $(\mathrm{n}=5)$ were isolated in 72,2 , and $5 \%$ of the samples, respectively $(\mathrm{n}=100 ; 32$ missing data). No bacterial growth was detected in $21 \%$ of the samples. In the enrofloxacin group, the number of quarters positive for $E$. coli on d 2 was lower than in the nontreated group $(P=0.002$, odds ratio for cure 3.32; data consisted of 98 in statistical analysis). The reasons for missing data $(\mathrm{n}=34)$ from the statistical analyses were lack of information on clinical signs on $d$ 0 (1 cow), use of fluid therapy (2 cow), and a missing milk sample on d 2 (31 cows).

On d 21, E. coli, other coliforms, other bacteria, and mixed growth were isolated from 14.5, 4.8, 22.9, and $4.8 \%$ of the samples, respectively $(\mathrm{n}=83 ; 49$ missing data). No bacterial growth was detected in $53.0 \%$ (44/83) of the samples. Bacteriological cure on d 21 was seen in 38 of 42 cows (90.5\%) in the enrofloxacin group and in 33 of 38 cows $(86.8 \%)$ in the nontreated group. Persistent E. coli infection; that is reisolation of the original $E$. coli pulsotype in the posttreatment sample on d 21, was detected in 9 quarters $(11.3 \%$ of 80 cases sampled at both occasions), 4 in the enrofloxacin and 5 in the nontreated group. In addition, 3 samples had growth of $E$. coli, but these isolates were not included in PFGE analysis and cases were excluded from this statistical analysis.

Milk from cows receiving fluid therapy had growth of $E$. coli on d 2 more often than cows that did not have fluid therapy $[P=0.05$; odds ratio (OR) for cure 0.24]. More severe signs on d 0 increased the risk of having $E$. coli growth in the milk sample on d $2(P=0.02$; 
Table 1. Descriptive statistics and univariable results of naturally occurring acute Escherichia coli mastitis ${ }^{1}$

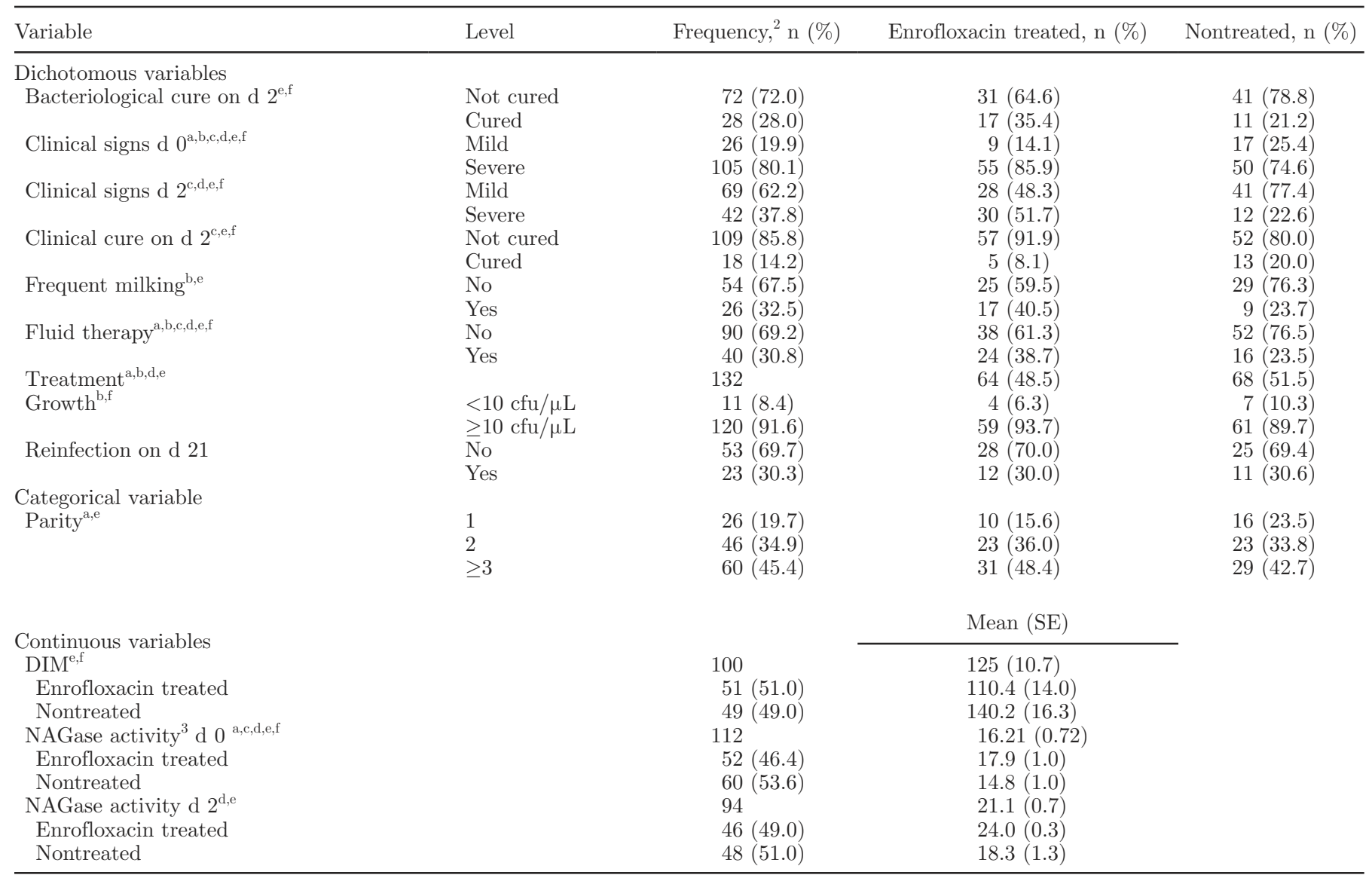

${ }^{a}$ Variables with $P<0.25$ in the univariable analyses of bacteriological cure on $\mathrm{d} 2$.

${ }^{b}$ Variables with $P<0.25$ in the univariable analyses of clinical cure on $\mathrm{d} 2$.

${ }^{c}$ Variables with $P<0.25$ in the univariable analyses of clinical cure on $\mathrm{d} 21$.

${ }^{\mathrm{d}}$ Variables with $P<0.25$ in the univariable analyses of NAGase activity on d 21 .

${ }^{\text {e}}$ Variables with $P<0.25$ in the univariable analyses of returning of quarter milk production.

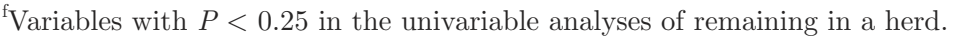

${ }^{1}$ In total, 61 herds and 132 cows were enrolled in the study. Cows were randomly assigned to be treated with enrofloxacin or left untreated.

${ }^{2} \mathrm{~A}$ total less than 132 for a whole variable indicates that data were missing.

${ }^{3} \mathrm{~N}$-acetyl- $\beta$-D-glucosaminidase measured in picomoles of 4-methylumbelliferone (4-MU) per minute per microliter.

OR for cure 0.22). None of the tested factors affected bacteriological cure on d 21 ( $\mathrm{n}=79$ in the analyses; Table 2). The reasons for missing data from the statistical analysis were no information $(\mathrm{n}=53)$ on clinical signs on d 0 (1 cow), samples with E. coli but no PFGE confirmation (3 cows), dead cows (8), regular drying-off (3 cows), or milk sample missing (38 cows).

\section{Clinical Cure}

Five cows (8.1\%) in the enrofloxacin group and 13 cows $(20.0 \%)$ in the nontreated group showed clinical cure on d 2. Enrofloxacin treatment decreased clinical cure on d 2 ( $P=0.016$; OR 0.05), but use of frequent milking improved clinical cure $(P=0.005$; OR 39.82).
Clinical cure was more common on $\mathrm{d} 2$ in cows that had milder systemic signs on d $0(P=0.002$; OR 0.25$)$. Data comprised 79 observations; the reasons for missing data $(\mathrm{n}=53)$ from the statistical analysis were no information in clinical signs on d 0 (1 cow), all data on d 2 (5 cows), or use of frequent milking (47 cows).

On d 21, 28 cows out of $60(46.7 \%)$ in the enrofloxacin group and 36 cows out of $63(57.1 \%)$ in the nontreated group were clinically cured. Enrofloxacin treatment had no significant effect on clinical cure on d 21 (Table 2). Cows that had been administered fluid therapy had a lower clinical cure score on d $21(P=0.02$; OR 0.24$)$. Clinical cure on d 2 improved clinical cure on d 21 $(P=0.035 ;$ OR 10.12). Data comprised 85 cases; the reasons for missing data $(\mathrm{n}=47)$ from the statistical 
Table 2. Results of multivariable mixed logistic regression analyses of factors associated with bacterial cure and clinical cure on d 21 after naturally occurring acute Escherichia coli mastitis ${ }^{1}$

\begin{tabular}{|c|c|c|c|c|c|c|c|}
\hline \multirow[b]{2}{*}{ Variable } & \multirow[b]{2}{*}{ Level } & \multicolumn{3}{|c|}{ Bacterial cure $(\mathrm{n}=79)$} & \multicolumn{3}{|c|}{ Clinical cure $(\mathrm{n}=85)$} \\
\hline & & OR & $95 \% \mathrm{CI}$ & $P$-value & OR & $95 \% \mathrm{CI}$ & $P$-value \\
\hline Clinical cure d 2 & No & & & & 1 & & \\
\hline & Yes & & & & 10.12 & $1.17-87.3$ & 0.035 \\
\hline Clinical signs d 2 & Mild & & & & 1 & & \\
\hline Enrofloxacin treatment & Yes & 1.73 & $0.41-7.34$ & 0.46 & 0.87 & $0.31-2.5$ & 0.8 \\
\hline \multirow[t]{2}{*}{ Fluid therapy } & No & & & & 1 & & \\
\hline & Yes & & & & 0.24 & $0.07-0.8$ & 0.02 \\
\hline NAGase $^{2}$ activity d 0 & & & & & 0.7 & $0.3-1.61$ & 0.4 \\
\hline Parity 1 & 1 & 1 & & & & & \\
\hline Parity 2 & 2 & 1.01 & $0.15-6.80$ & 0.99 & & & \\
\hline Parity $\geq 3$ & 3 & 2.46 & $0.34-17.67$ & 0.37 & & & \\
\hline
\end{tabular}

${ }^{1}$ Cows were randomly assigned to be treated with enrofloxacin or left untreated. Odds ratio (OR) and CI indicate the risk for cure.

${ }^{2} \mathrm{~N}$-acetyl- $\beta$-D-glucosaminidase [measured in pmol of 4-methylumbelliferone (4-MU) per min $/ \mu \mathrm{L}$ ].

analysis were no information on the clinical signs on $\mathrm{d} 2$ (19 cows), use of fluid therapy (2 cows), lack of clinical data on d 21 (9 cows), or lack of samples for testing of NAGase activity on d 0 (17 cows).

\section{Milk NAGase}

Milk NAGase activity on d 21 was associated with severity of the clinical signs on d 0 ; the more severe the signs, the higher the NAGase activity on d $21(P=$ 0.007). Use of frequent milking decreased milk NAGase activity on $\mathrm{d} 21(P=0.04)$. None of the other factors were significantly related to milk NAGase activity on d 21 (Table 3). Data consisted of 32 cases; the reasons for missing data $(\mathrm{n}=100)$ from the statistical analysis were no information on the clinical signs on d 0 (1 cow), no information on use of frequent milking (33), no information on milk NAGase activity on d 0 (17 cows), dead (8 cows), regular drying-off (4 cows), no milk sample on d 21 (14 cows), or reinfection (23 cows).

\section{Return of Quarter Milk Production}

Quarter milk production returned to preinfection levels in $31(29.3 \%)$ cows and was diminished (not returned) in 70 (includes 31 cows with a blind quarter; $69.3 \%)$ cases $(\mathrm{n}=101 ; 31$ missing data). In the enrofloxacin group, quarter milk production returned in $21.8 \%(\mathrm{n}=12)$ of cows and in the nontreated group in $37.3 \%(\mathrm{n}=19)$ of the cows.

More severe clinical signs on d 0 impaired the returning of quarter milk production as estimated on d 21 $(P=0.02$, OR 16.2). The other variables had no effect on the returning of quarter milk production (Table 4). Forty-eight cases were included in the analysis. The reasons for missing data (84) were no information on the clinical signs on d 0 (1 cow), use of fluid therapy (2 cows), frequent milking (31 cows), or returning of quarter milk production (17 cows); and regular dryingoff (7 cows), reinfection (22 cows), or mixed growth in sample on d 21 (4 cows).

\section{Survival and Remaining in the Herd}

Three cows in the enrofloxacin group and 5 in the nontreated group of 132 did not survive (i.e., died or were killed) by d 21 posttreatment. None of the cows were culled for any reasons during the period of $21 \mathrm{~d}$. Cows that did not survive were all classified as severe

Table 3. Results of multiple linear regression analysis of factors associated with milk N-acetyl- $\beta$-Dglucosaminidase (NAGase) activity on d 21 after naturally occurring acute Escherichia coli mastitis ${ }^{1}$

\begin{tabular}{lccc}
\hline Variable & Coefficient & \multicolumn{1}{c}{$95 \%$ CI } & $P$-value \\
\hline Clinical signs d 0 & 1.208 & 0.352 to 2.063 & 0.007 \\
Enrofloxacin treatment & 0.174 & -0.538 to 0.886 & 0.62 \\
Frequent milking used & -0.752 & -1.479 to -0.025 & 0.043 \\
NAGase activity d 0 & 0.482 & -0.073 to 1.036 & 0.086 \\
Constant & -0.412 & -1.807 to 0.984 & 0.55 \\
\hline
\end{tabular}

${ }^{1}$ The data set consisted of 32 cases. Cows were randomly assigned to be treated with enrofloxacin or left untreated. Coefficient indicates the effect of the variable to tissue damage and inflammation in the mammary gland reflected by milk NAGase activity [measured in pmol of 4-methylumbelliferone (4-MU) per min/ $\mu \mathrm{L}$ ]. 
Table 4. Results of multivariable mixed logistic regression analyses of factors associated with return of quarter milk production on d 21 and remaining in the herd 6 mo after naturally occurring acute Escherichia coli mastitis ${ }^{1}$

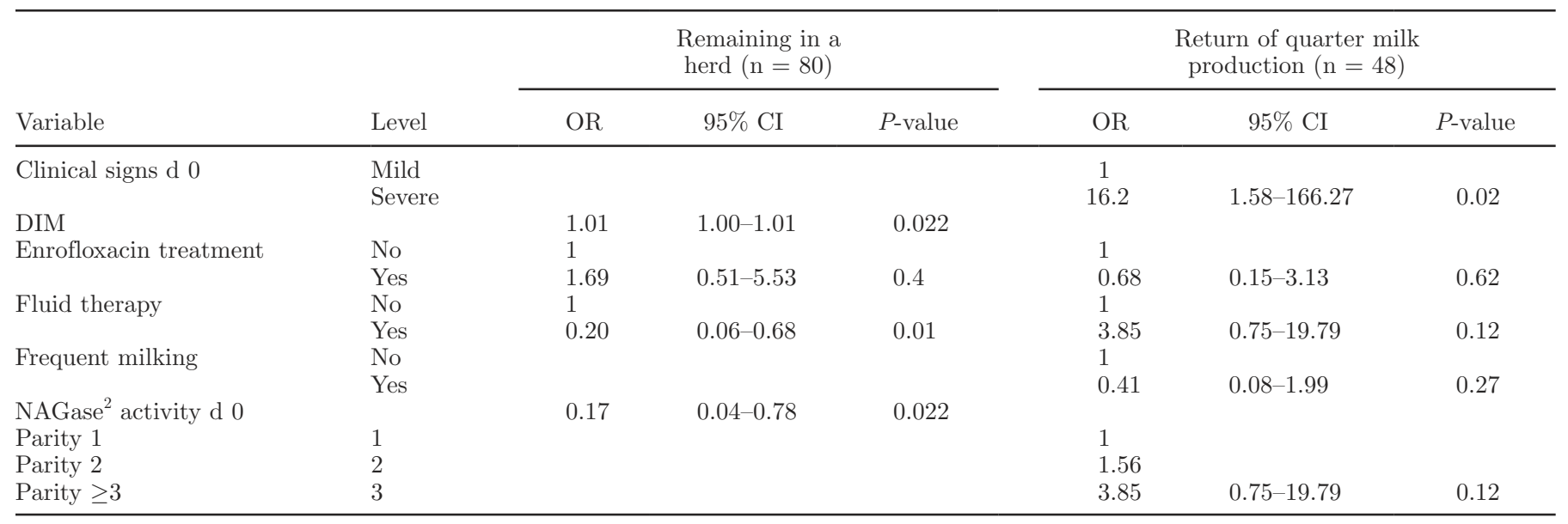

${ }^{1}$ Cows were treated randomly with enrofloxacin or left untreated. Odds ratio (OR) indicates the risk for remaining in the herd or return of quarter milk production.

${ }^{2} \mathrm{~N}$-acetyl- $\beta$-D-glucosaminidase [measured in pmol of 4-methylumbelliferone (4-MU) per min/ $\left.\mu \mathrm{L}\right]$.

cases on d 0. Enrofloxacin had no effect on survival of the cow during the period of $21 \mathrm{~d}$ (Table 5 ).

Of all cows, 31 (23.5\%; 18 in the enrofloxacin group and 13 in the nontreated group) left the herd during the 6-mo follow-up (Table 4). Enrofloxacin had no effect on remaining in the herd 6 mo after treatment. Analysis was based on 80 cases; the reasons for missing data (n $=52$ ) were no information on remaining in the herd (1 cow), use of fluid therapy (2 cows), DIM (32 cows), or NAGase activity on d 0 (17 cows).

\section{DISCUSSION}

Systemic enrofloxacin treatment did not result in greater bacteriological or clinical cure of acute clinical mastitis caused by E. coli compared with supportive treatment alone when assessed $21 \mathrm{~d}$ posttreatment. Moreover, enrofloxacin treatment did not affect survival of the cows, return of quarter milk production, or tissue damage of the affected quarter by $3 \mathrm{wk}$ posttreatment, nor did it affect whether the cow remained in the herd during the 6-mo follow-up. The only positive effect of enrofloxacin treatment was the better bacteriological cure on d 2 posttreatment, but clinical cure on $\mathrm{d} 2$ was lower in the enrofloxacin group. Clinical cure on d 21 was rather low in both groups, which may reflect the stringent criteria used to define clinical cure (no systemic signs, quarter free from any clinical signs, milk acceptable for delivery), but also the severe nature of E. coli mastitis. Parenteral administration of antimicrobials was recommended for the treatment of severe coliform mastitis (Cebra et al., 1996; Wenz et al., 2001), mainly because of the risk of bacteremia. Enrofloxacin is one of the antimicrobial drugs recommended for treatment of coliform mastitis because of its favorable pharmacokinetic and pharmacodynamic properties (Constable et al., 2008). The MIC values for ciprofloxacin or enrofloxacin of $E$. coli isolates from mastitis are low, and resistance of $E$. coli to fluoroquinolones is rare (FINRES-Vet, 2007). All isolates in our

Table 5. The results of survival of the cow during the 3-wk study period in naturally occurring acute Escherichia coli mastitis studied in simple logistic regression analyses, variables $P<0.05$ and effect of enrofloxacin presented ${ }^{1}$

\begin{tabular}{|c|c|c|c|c|c|}
\hline Variable & Cows, $n$ & Level & $\mathrm{OR}^{2}$ & $95 \% \mathrm{CI}$ & $P$-value \\
\hline Clinical signs d 2 & 111 & Mild & 1 & $001 \_04$ & 0.04 \\
\hline \multirow[t]{2}{*}{ Enrofloxacin treatment } & 132 & No & 1 & (1) & 0.04 \\
\hline & & Yes & 1.61 & $0.37-7.05$ & 0.52 \\
\hline \multirow[t]{2}{*}{ Fluid therapy } & 130 & No & 1 & & \\
\hline & & Yes & 0.06 & $0.01-0.55$ & 0.01 \\
\hline
\end{tabular}

${ }^{1}$ Cows were randomly assigned to be treated with enrofloxacin or left untreated.

${ }^{2}$ Odds ratio (OR) and CI indicate the risk for survival. 
study were found susceptible to ciprofloxacin in vitro. The administered dosage of enrofloxacin should have been sufficient to reach therapeutic concentrations in the udder and after s.c. administration (Rantala et al., 2002).

Enrofloxacin treatment significantly decreased milk loss determined $2 \mathrm{~d}$ posttreatment and alleviated local signs in the affected quarter $24 \mathrm{~h}$ posttreatment (Dosogne et al., 2002) in experimentally induced E. coli mastitis. In our study, enrofloxacin did not affect return of quarter milk production evaluated at $3 \mathrm{wk}$ posttreatment. The return of quarter milk production was estimated by the farmer, which is subjective; the results must be interpreted with caution. A faster elimination of bacteria from the quarter was reported in cows treated with enrofloxacin than in nontreated cows (Rantala et al., 2002). Poutrel et al. (2008) tested another fluoroquinolone, danofloxacin, in an experimental E. coli mastitis model. Danofloxacin significantly reduced the decrease in the milk production and lowered SCC and udder inflammation scores assessed 3 wk posttreatment. The initial clearance of bacteria from the quarters was faster in the danofloxacin group, but the final bacteriological cure was similar to that in the untreated group.

Previous studies on the efficacy of antimicrobial therapy in naturally occurring coliform mastitis are few. In one study, systemic ceftiofur therapy was shown to favorably influence the outcome of severe cases of coliform mastitis (Erskine et al., 2002). In contrast, Katholm and Andersen (1998) showed in a Danish field trial using a nonantibiotic therapy regimen that antimicrobial therapy provided no advantage, at least in the treatment of mild and moderate cases of coliform mastitis. The immune response of the cow seems to play a major role in defense against $E$. coli infection in the mammary gland, and this response varies greatly among individual cows (Burvenich et al., 2003).

The clinical cure of enrofloxacin-treated cows here was inferior compared with that for the untreated cows. In theory, this could be because of a release of endotoxin after the more efficient killing of bacteria. Release of endotoxin from killed gram-negative bacteria after antimicrobial treatment was considered a risk in humans (Lepper et al., 2002). However, Dosogne et al. (2002), using an experimentally induced E. coli model, showed that endotoxin levels did not differ in enrofloxacin-treated and untreated cows, which does not support this theory.

Frequent milking, a traditional treatment for mastitis, is commonly recommended as a supportive treatment of severe mastitis in Finland. Our findings indicate that frequent milking at the acute stage of mastitis may improve the initial clinical cure of E. coli mastitis and thus, decrease inflammation and tissue damage in the infected quarter.

In 9 cases (11\%), the same genotype of E. coli was isolated from the affected quarter at $3 \mathrm{wk}$ posttreatment, indicating persistence of the same genotype of $E$. coli in the quarter. This figure is much lower than the $20.5 \%$ reported in a UK study by Bradley and Green (2001), but close to the $12.4 \%$ reported in an earlier Finnish study (Lehtolainen et al. 2003). The abovementioned UK study included only 6 herds, which may have affected the results. In our study, posttreatment samples were stored frozen, which can influence growth of E. coli and decrease the frequency of reisolation. The number of quarters harboring growth of bacteria other than the original E. coli at 3 wk posttreatment was high $(30.3 \%)$. One explanation for this could be that mastitic milk was a better growth medium for mastitis bacteria than milk from healthy quarters (Mattila et al., 1984).

The proportion of cows that died or were killed during the $3 \mathrm{wk}$ after treatment $(6 \%)$ was lower in our study than in American field studies (22\% in Wenz et al., 2001; 27\% in Cebra et al., 1996). The former study had a follow-up period of $4 \mathrm{wk}$, and lost cows included all cows culled; the latter was carried out in a teaching hospital clinic, which may mean that cows with severe disease were included. Factors such as breed, milk yield, management, environment, and herd size may explain the differences. The proportion of affected cows removed from the herd within 6 mo was $23.5 \%$ in this study, indicating a high risk for a cow culled after contracting E. coli mastitis. Escherichia coli mastitis is known to cause a long-lasting decrease in milk production of the affected quarter (Golodetz and White, 1983). Somatic cell count remains high (Pyörälä and Pyörälä, 1997) and the risk for reinfection in the affected quarter increases, resulting in culling of the cow. The significant association between remaining in the herd and DIM may indicate that a cow was more likely to be kept in the herd if it was in late lactation and drying-off was approaching.

Our study did not support the use of enrofloxacin to treat acute clinical E. coli mastitis, although enrofloxacin may have facilitated faster elimination of bacteria. Antimicrobial therapy could reduce the number of bacteria in severe cases and provide time for the immune system to act (Rantala et al., 2002). The risk of bacteremia should be considered (Wenz et al., 2001). Bacterial count in the initial sample could represent a valuable tool for the cattle practitioner in weighing the need for antimicrobial therapy and the prognosis of the cow (Katholm and Andersen, 1998). In severe cases of E. coli mastitis, tissue damage may be too advanced for antimicrobial therapy to offer any significant ben- 
efit (Hill, 1984; Vandeputte-Van Messom et al., 1993). Fluoroquinolones, a group that includes enrofloxacin, are critically important antimicrobials in human and veterinary medicine (Collignon et al., 2009) and should be used only for severe infections and when their efficacy has been confirmed.

\section{ACKNOWLEDGMENTS}

This work was supported by grants from the Walter Ehrström Foundation (Helsinki, Finland), the Mercedes Zachariassen Foundation (Helsinki, Finland), the Finnish Veterinary Foundation (Helsinki, Finland), the EVO Fund of Lammi-Tuulos Health Centre (Lammi, Finland), and the Häme Regional Foundation of the Finnish Cultural Foundation (Hämeenlinna, Finland). Orion Pharma Animal Health kindly provided us with Baytril and Comforion, and Vetcare with Carepen. We thank Anna-Liisa Myllyniemi, Anna Pitkälä, and Tarja Pohjanvirta in the Finnish Food Safety Authority Evira (Helsinki, Finland) for final identification, MIC determination, and PFGE analysis of the isolates. We thank also the veterinarians and the clients of the veterinary practices for their participation in the field trial and the laboratory staff at the Department of Production Animal Medicine for collaboration in this study.

\section{REFERENCES}

Banting, A., S. Banting, K. Heinonen, and K. Mustonen. 2008. Efficacy of oral and parenteral ketoprofen in lactating cows with endotoxininduced acute mastitis. Vet. Rec. 163:506-509.

Bradley, A. J., and M. J. Green. 2001. Adaptation of Escherichia coli to the bovine mammary gland. J. Clin. Microbiol. 39:1845-1849.

Burvenich, C., V. Van Merris, J. Mehrzad, A. Diez-Fraile, and L. Duchateau. 2003. Severity of E. coli mastitis is mainly determined by cow factors. Vet. Res. 34:521-564.

CDC (Centers for Disease Control and Prevention). 2008. PulseNet Protocols. http://www.cdc.gov/pulsenet/protocols.htm Accessed Oct. 10, 2008.

Cebra, C. K., F. Garry, and R. Dinsmore. 1996. Naturally occurring acute coliform mastitis in Holstein cattle. J. Vet. Intern. Med. 10:252-257.

CLSI. 2004. Performance standards for antimicrobial disk and dilution susceptibility tests for bacteria isolated from animals, informational supplement. CLSI document M31-S1. Clinical Laboratory Standards Institute (CLSI), Wayne, PA.

Collignon, P., J. Powers, T. Chiller, A. Aidara-Kane, and F. Aarestrup. 2009. World Health Organization ranking of antimicrobials according to their importance in human medicine: A critical step for developing risk management strategies for the use of antimicrobials in food production animals. Clin. Infect. Dis. 49:132-141.

Constable, P., S. Pyörälä, and G. Smith. 2008. Guidelines for antimicrobial use in cattle. Pages $143-160$ in Antimicrobial Use in Animals. L. Guardabassi, L. B. Jensen, and H. Kruse, ed. Blackwell Publishing Ltd., Oxford, UK.

Dosogne, H., E. Meyer, A. Sturk, J. van Loon, A. Massart-Leën, and C. Burvenich. 2002. Effect of enrofloxacin treatment on plasma endotoxin during bovine Escherichia coli mastitis. Inflamm. Res. $51: 201-205$.
Erskine, R. J., P. Bartlett, J. VanLente, and R. Phipps. 2002. Efficacy of systemic ceftiofur as a therapy for severe clinical mastitis in dairy cattle. J. Dairy Sci. 85:2571-2575.

Fang, W., and S. Pyörälä. 1996. Mastitis-causing Escherichia coli: Serum sensitivity and susceptibility to selected antibacterials in milk. J. Dairy Sci. 79:76-82.

FINRES-Vet. 2007. FINRES-Vet 2005-2006: Finnish veterinary antimicrobial resistance monitoring and consumption of antimicrobial agents. Evira Publications 22/2007. http://www. evira.fi/uploads/WebShopFiles/1198141211941.pdf Accessed Jan. 28, 2009.

Golodetz, C. L., and M. E. White. 1983. Prognosis for cows with severe clinical coliform mastitis. Vet. Rec. 112:402-403.

Hill, A. W. 1984. Progressive pathology of severe Escherichia coli mastitis in dairy cows. Res. Vet. Sci. 37:179-187.

Hoeben, D., H. Dosogne, R. Heynman, and C. Burvenich. 1997. Effect of antibiotics on the phagocytotic and respiratory burst activity of bovine granulocytes. Eur. J. Pharmacol. 332:289-297.

Hogan, J., R. Gonzales, R. Harmon, S. Nickerson, S. Oliver, J. Pankey, and K. Smith. 1999. Laboratory Handbook on Bovine Mastitis. National Mastitis Council, Madison, WI.

IDF. 1999. Suggested interpretation of mastitis terminology. Smith, K. coordinator. Bulletin no. 338:3-26. International Dairy Federation, Brussels, Belgium.

Jones, G. F., and G. E. Ward. 1990. Evaluation of systemic administration of gentamicin for treatment of coliform mastitis in cows. J. Am. Vet. Med. Assoc. 197:731-735.

Kaartinen, L., M. Salonen, L. Älli, and S. Pyörälä. 1995. Pharmacokinetics of enrofloxacin after single intravenous, intramuscular and subcutaneous injections in lactating cows. J. Vet. Pharmacol. Ther. 18:357-362.

Katholm, J., and P. Andersen. 1998. Severe coliform mastitis in practice: Efficacy of the therapy regimen not including antibiotics. Pages 261-264 in Proc. XX World Buiatrics Congress, Sydney, Australia.

Lehtolainen, T., A. Shwimmer, N. Shpigel, T. Honkanen-Buzalski, and S. Pyörälä. 2003. In vitro antimicrobial susceptibility of Escherichia coli isolates originating from clinical mastitis in Finland and Israel. J. Dairy Sci. 86:3927-3932.

Lepper, P. M., T. Held, E. Schneider, E. Bölke, H. Gerlach, and M. Trautmann. 2002. Clinical implications of antibiotic-induced endotoxin release in septic shock. Intensive Care Med. 28:824833.

Lohuis, J. A., W. Van Leeuwen, J. Verheijden, A. Brand, and A. Van Miert. 1989. Flunixin meglumine and flurbiprofen in cows with experimental Escherichia coli mastitis. Vet. Rec. 124:305-308.

Mattila, T., and M. Sandholm. 1986. Milk plasmin, N-acetyl-betaD-glucosaminidase, and antitrypsin as determinants of bacterial replication rates in whey. J. Dairy Sci. 69:670-675.

Mattila, T., J. Syväjärvi, and M. Sandholm. 1984. Bacterial growth in whey from mastic and nonmastitic quarters. Am. J. Vet. Res. $45: 1-3$

McDougall, S., M. Bryan, and R. Tiddy. 2009. Effect of treatment with the nonsteroidal anti-inflammatory meloxicam on milk production, somatic cell count, probability of re-treatment, and culling of dairy cows with mild clinical mastitis. J. Dairy Sci. 92:4421-4431.

Poutrel, B., M. Stegemann, O. Roy, F. Pothier, N. Tilt, and M. PayneJohnson. 2008. Evaluation of the efficacy of systemic danofloxacin in the treatment of induced acute Escherichia coli bovine mastitis. J. Dairy Res. 75:310-318.

Pyörälä, S., L. Kaartinen, H. Käck, and V. Rainio. 1994. Efficacy of two therapy regimens for treatment of experimentally induced Escherichia coli mastitis in cows. J. Dairy Sci. 77:453-461.

Pyörälä, S., and E. Pyörälä. 1997. Accuracy of methods using somatic cell count and milk N-acetyl- $\beta$-D-glucosaminidase activity in milk to assess the bacteriological cure of bovine clinical mastitis. J. Dairy Sci. 80:2820-2825.

Pyörälä, S. H., and E. O. Pyörälä. 1998. Efficacy of parentera administration of three antimicrobial agents in treatment of 
clinical mastitis in lactating cows: 487 cases (1989-1995). J. Am. Vet. Med. Assoc. 212:407-412.

Rantala, M., L. Kaartinen, E. Välimäki, M. Stryrman, M. Hiekkaranta, A. Niemi, L. Saari, and S. Pyörälä. 2002. Efficacy and pharmacokinetics of enrofloxacin and flunixin meglumine for treatment of cows with experimentally induced Escherichia coli mastitis. J. Vet. Pharmacol. Ther. 25:251-258.

Shpigel, N. Y., R. Chen, M. Winkler, A. Saran, G. Ziv, and F. Longo. 1994. The anti-inflammatory ketoprofen in the treatment of field cases of bovine mastitis. Res. Vet. Sci. 56:62-68.
Vandeputte-Van Messom, G., C. Burvenich, E. Roets, A.-M. MassartLeën, R. Heyneman, W. Kremer, and A. Brand. 1993. Classification of newly calved cows into moderate and severe responders to experimentally induced Escherichia coli mastitis. J. Dairy Res. 60:19-29

Wenz, J. R., G. Barrington, F. Garry, K. McSweeney, R. Dinsmore, G. Goodell, and R. Callan. 2001. Bacteremia associated with naturally occurring acute coliform mastitis in dairy cows. J. Am. Vet. Med. Assoc. 219:976-981. 